Pignotti, Chiara.

PhD. Arte: Producción e investigación, Universidad Politécnica de Valencia.

\title{
La influencia de la globalización en la joyería mexicana.
}

\section{The influence of the globalisation in the Mexican jewellery.}

\author{
TIPO DE TRABAJO: \\ Comunicación. \\ PALABRAS CLAVE: \\ Joyería Contemporánea, globalización, mexicanismo. \\ KEY WORDS: \\ Contemporary jewellery, globalization, mexicanism.
}

RESUMEN.

La joyería es una de las manifestaciones artísticas que más exprime la identidad de un pueblo, sus creencias, sus valores y sus preferencias estéticas. Por esto el estudio de la joyería mexicana en la actualidad puede darnos una visión panorámica de cómo la globalización ha cambiado la concepción, el uso y el consumo de este producto artístico. A partir de los opuestos procesos de desterritorialización, por parte de las maniobras de la economía global, y de reterriorialización como respuestas de las realidades locales, delinearemos algunas emblemáticas situaciones que la joyería mexicana está viviendo.

La desterritorialización conlleva radicales cambios en la definición de arte popular, ámbito al que la joyería tradicional pertenece; efectivamente el "valor moda" que las multinacionales aplican a su producción hizo de la joyería comercial la principal joyería popular en México. Mientras que la joyería hecha por el pueblo se convierte en un producto elitista para un mercado exclusivo y de coleccionismo, por el otro lado, en su manifestación más sencilla, se convierte en un souvenir para el turista.

Entre los efectos prominentes de la reterritorialización hemos averiguado la exaltación del mexicanismo hasta convertirse en "auto exotismo". Este proceso está evidente en la recuperación de los símbolos y cualidades apotropaicas de la joyería prehispánica por parte de neo-chamanes, artesanos y artistas como reafirmación de la propia cultura original. Es en este contexto que surge la Joyería Contemporánea mexicana, cuyo análisis nos hará reflexionar sobre como actúa la influencia mediática de los fenómenos artísticos internacionales en los contextos locales.

\section{ABSTRACT.}

Jewellery, among all the arts, is the one that expresses the identity of people, their beliefs, values and aesthetic preferences the most and especially in the last decade, was strongly influenced by globalization. Mexican jewellery today can give us a good view of how globalization changed the concept and use of this artistic product. From two opposing processes, the manoeuvres of the global economy and the responses of local realities, we will outline some emblematic situations that Mexican jewellery is experiencing.

The global economy carries radical changes in the definition of popular art, an area to which traditional jewellery belongs. We can see the "fashion value" created by multinationals groups making commercial jewellery, the main popular one in Mexico. While the jewellery made by the artisan becomes an elitist product for an exclusive market and collection or, in its simplest manifestation, it becomes a souvenir for the tourist. 
Among the prominent effects of globalization we have determined that mexicanism became a sort of self-imposed exoticism. This process is evident in the recovery of apotropaic symbols and qualities of pre-Hispanic jewellery by neoshamans, artisans and artists as a reaffirmation of their own original culture. It's in this latter case that the analysis of Mexican Contemporary Jewellery will make us reflect on how the media influence of international artistic phenomena acts in local contexts.

\section{CONTENIDO}

En México, así como en los otros países latinoamericanos que han sido colonizados, sigue siendo difícil recuperar una propia autonomía cultural tras las violencias sufridas a partir de la identidad negada. El proceso de modernización y la sucesiva globalización han conllevado la creación de centros hegemónicos, donde el arte se juzga y se selecciona, en contraposición a otras lecturas del arte, que surgen desde contextos locales, desde otras raíces culturales. Así como los estudios y la crítica del arte desde Latinoamérica también nosotros emplearemos los términos de "centro" y "periferia" para remarcar la existencia de dicha dicotomía. En estos países coexisten una cultura "central", que hace referencia al arte y mercado internacional, y una pluralidad de culturas "periféricas" donde sobreviven las artes populares, las lenguas y las costumbres locales. En este contexto la joyería tiene que ver tanto con las identidades urbanas globalizadas, que tienden a la adquisición de productos y modas internacionales, como también con la identidad local que se conserva por medio de la joyería étnico tradicional. Entre estos dos frentes se posiciona la Joyería Contemporánea, movimiento artístico internacional que promueve la joyería concebida como forma de expresión artística personal. Este tipo de producto artístico está por un lado más próximo a la cultura urbana y global, y por el otro se retroalimenta de la cultura local, de la cual recupera materiales, técnicas y símbolos que puedan servir para la recodificación de nuevas y múltiples identidades actuales a través del objeto joya.

Desde nuestro estudio de campo en México hemos podido analizar a través de la joyería como las dinámicas inherentes a la economía y cultura global están cambiando la identidad local. Nos apoyamos a los términos acuñados por Franco Beradi ${ }^{1}$ para distinguir dos dinámicas culturales actualmente en acto: la desterritorialización, con la que identificamos el avance territorial del control y acción del poder central, y la reterritorialización como respuesta de las realidades locales. A través de la desterritorialización el poder central se apropia de la simbología tradicional y ejerce la reorientación de los valores populares hacia sus intereses. Es lo que Berardi define como sobredeterminación semiótica, es decir la apropiación y recodificación de los símbolos tradicionales, así como la reorientación de los valores populares hacia los intereses del capitalismo. Esta estrategia se sirve del poder seductivo de los medios publicitarios y del espectáculo para crear valores añadidos a determinados productos, en distintos ámbitos como podría ser la industria de la moda y del turismo.

En la joyería mexicana estas fuerzas opuestas determinan un drástico cambio en su concepción, uso y consumo. En primer lugar cambia el concepto de joyería popular, donde la mayoría de los consumidores prefieren productos de las famosas firmas internacionales, respecto a la joyería étnico tradicional. ${ }^{2}$ Esta última, tradicionalmente producida y consumida por el sector popular, se ha dividido entre la producción artesanal más autentica que se ha convertido en un producto de elite y la producción más comercial, que ha llegado a ser un simple souvenir. En la industria del turismo el imaginario local está reformulado por un mecanismo que fuerza las realidades locales a permanecer en un eterno presente donde el traje tradicional se convierte en un disfraz, que responde a la demanda de lo que pretende ver (o quizás mejor dicho "fotografiar") el turista. Todo esto prejuzga el conjunto de las vivencias comunitarias, transformando artesanía y fiestas populares en folklor que atrae a los turistas y tranquiliza, de alguna manera, la esquizofrénica identidad del individuo urbanizado. Reconocemos aquí por un lado la desterritorialización cultural de los indígenas a través de la transformación de su modus vivendi, y por el otro lado la aplicación de un imaginario mediático, la sobredeterminacón semiótica, a productos artesanales, dando como resultado un doble vacío de significado del objeto artesanal. En las intenciones de quien vende y de quien compra este tipo de joyería se desconoce la compleja expresión simbólica y de los valores reales que sustentan la antigua cultura de una determinada comunidad. Esta situación ha conllevado una tendencia al "auto-exotismo", práctica frecuente que, más o menos conscientemente, se manifiesta en el arte y artesanías contemporáneas mexicanas.

El interés hacia otras culturas ha introducido una nueva sed de exotismo, lo que Gerardo Mosquera define como un "eurocentrismo pasivo" o de "segunda instancia"; ${ }^{3}$ desde los centros se pretende encontrar en las producciones culturales periféricas aquellos elementos que respondan a los estereotipos de un determinado lugar, condicionando la representación artística, como en el caso de

\footnotetext{
${ }^{1}$ BERARDI F. La fábrica de la infelicidad. Madrid: Ed. Traficantes de Sueños. 2003.

${ }^{2}$ Confr. con: MARCOS MARTÍNEZ, C.; PIGNOTTI, C. La recuperación de la manualidad frente a la crisis impuesta por la cultura globalizadora dominante. En: I Congreso de Investigación en Artes Visuales: El Arte Necesario. Valencia: Ed. ANIAV- DEFORMA Cultura On line, 2013. ISSN 2254-2272.

${ }^{3}$ MOSQUERA, G. Caminar con el diablo. Textos sobre arte, internacionalismo y culturas. Madrid: Ed. EXIT Publicaciones, 2010. Pág. 32.
} 
las artesanías para turistas en las que se exageran los rasgos locales o primitivos, para vender mejor. De estas dinámicas se hace evidente el fetichismo occidental hacia las otras culturas tanto como las necesidades de los artistas y artesanos de ajustarse a la demanda del mercado, como la inclusión de las imágenes de Frida Kahlo, de los personajes de los grabados de Posada o de la famosa Catrina en la joyería mexicana.

La joyería étnico tradicional puede ser sustituida también por modas que surgen de las subculturas urbanas como la adopción del estilo punk por parte de los jóvenes de la etnia mazahua. En cambio la joyería tradicional mazahua sigue siendo de un altísimo nivel de calidad artesanal y de representación cultural, siendo una de las más apreciadas por la alta clase mexicana y por los extranjeros. En el contexto actual no hay posibilidad de salida para este tipo de joyería u otras artesanías locales, porque ya no se pueden sustentar con el comercio local y carecen de las estrategias del marketing necesarias para la ubicación del producto en el mercado, con la consiguiente descontextualización y pérdida de éstos conocimientos. Desde estas nuevas necesidades surgen interesantes proyectos colaborativos entre diseñadores, que suelen formarse desde un contexto universitario e urbano, y todas categorías de artesanos, que por lo contrario, suelen trabajar en pequeñas aldeas según la tradición familiar y comunitaria. En el caso de la joyería, proyectos como UKUM, joyería de origen, de la joven diseñadora Emilia Córdoba, podrían ser un ejemplo de reterritorialización, siendo su objetivo recalificar la joyería étnico tradicional apuntando a la difusión del conocimiento del trabajo de los artesanos, evidenciar su importancia cultural y artística, exaltando la belleza relacionada a específicas identidades locales, creando un branding muy preciso y avalándose de otras estrategias de marketing. De esta manera Emilia Córdoba está consiguiendo posicionar la joyería tradicional entre la alta clase mexicana, creando puntos de venta en lugares estratégicos como Valle de Bravo, o el barrio capitalino de San Ángel, y vendiendo a nivel internacional por medio de Novica la tienda on line de National Geographic.

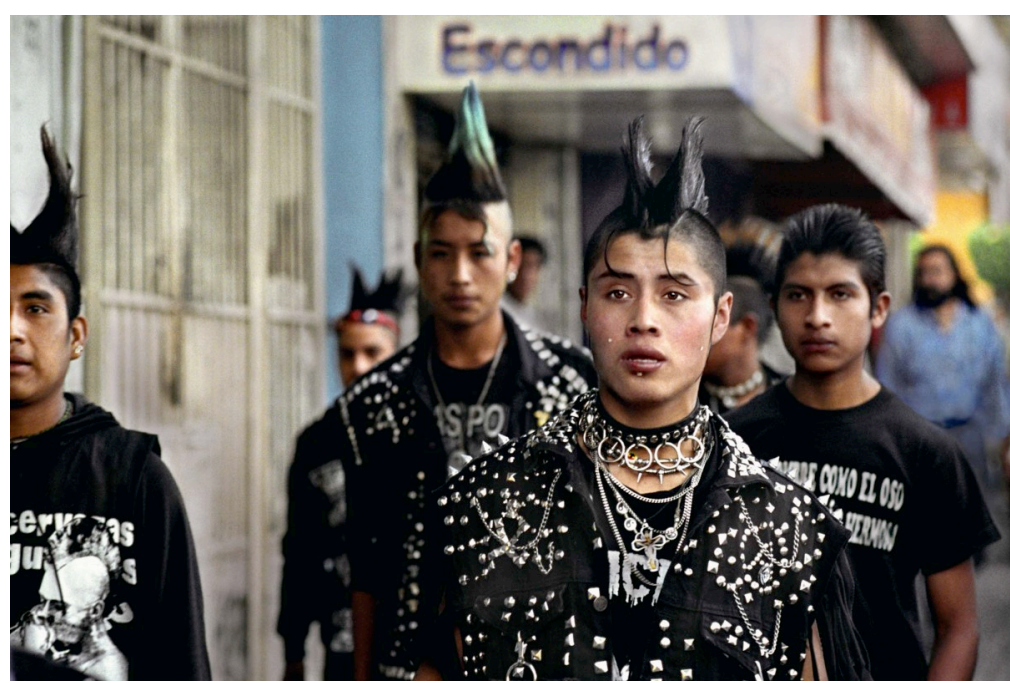

Ilustración 1. Imagen de algunos jóvenes mazahua que a los atavíos tradicionales prefieren adoptar el estilo punk. Fuente: GAMA F. Mazahua choloskato punk. En: Textiles Mazahuas. Ed. Revista Artes de México.N.102. México. Junio de 2011.

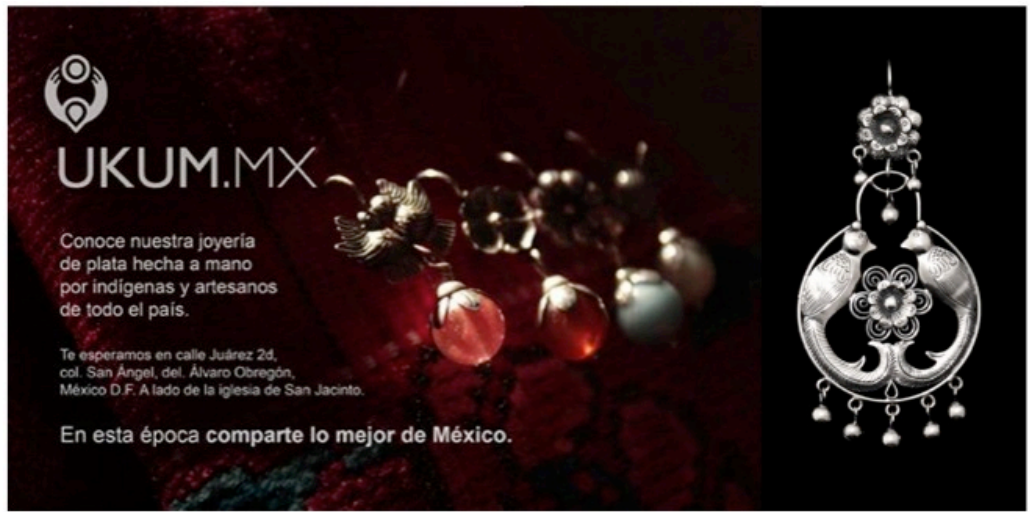

llustración 2. Joyería tradicional mazahua presentada por el proyecto UKUM, joyería de origen. 
Entre otros efectos resultantes de la constante tensión entre desterritorialización y reterritorialización podemos encontrar la revitalización o invención de tradiciones y localismos que conllevan la creación de nuevos géneros de subcultura, recuperando el pasado a través de lo contemporáneo en la construcción de distintas posibilidades de un neo mexicanismo. De aquí surge el movimiento Mexicanista, desde el cual se hace evidente que la reafirmación de la cultura autóctona pasa por una reinterpretación de las tradiciones prehispánicas recreando una imagen idealizada del indígena. El problema es querer reafirmar unas raíces culturales supuestamente originales desde una realidad demasiado diferente y compleja, por medio de las tecnologías de la información y comunicación aptas para un proceso que hace ambiguas o incluso ausentes las fuentes de enunciación. ${ }^{4}$ Significativo es el hecho de que el movimiento mexicanista no surge entre las comunidades indígenas, sino más bien en los centros urbanos. En su mayoría los integrantes son de clase media con cierto nivel de estudios, incluyendo la adhesión de muchos extranjeros con inclinaciones místicas. El sincretismo se percibe también en las celebraciones que comprenden las conmemoraciones de fechas importantes tanto para la cultura prehispánica como para la católica, incluyendo recientes acontecimientos como el de la masacre de los estudiantes en Tlatelolco en 1968. Según el experto Francisco De la Peña, el mexicanismo es una continua reconfiguración simbólica que intenta dar una solución a la necesidad de estabilidad identitaria: "Se puede inscribir en el marco de lo que Augé ha llamado una antropología de los mundos contemporáneos (...) Por ello, el retorno a la tradición es menos una vuelta al pasado que una interpretación del presente, un mecanismo adaptativo que puede manifestarse de diferentes formas, pero que tiene por función absorber el choque que engendra el proceso de sobremodernización, otorgándole un sentido y una orientación ". ${ }^{5}$

Desde estas experiencias aparece un nuevo tipo de joyería, parte activa en el establecer el simbolismo que sustente esta nueva cultura, que tiene que ver con los bailes y rituales, empleando los elementos naturales por sus poderes energéticos, como el jade, la obsidiana o las plumas, según la tradición prehispánica. El artesano taxqueño Humberto Ortiz nos comenta de la existencia de un público exclusivo que busca piezas de esta especie, un público interesado en la cultura prehispánica, que le encarga piezas talladas en ámbar o jade, sobre todo con motivo del homenaje anual a Cuauchtémoc, en el pueblo de Ixateopan. De la Peña hace evidente que el hecho de que las reconstrucciones del mundo prehispánico sean irreales es significativo porque reenvía a un fenómeno generalizado en nuestros días, la reconstrucción de un imaginario colectivo por medio de las imágenes mediáticas cuya dimensión ficcional es notable, perdiendo la dimensión de lo real y del sentido histórico, generando una vacuidad perceptible en todos los fenómenos contemporáneos culturales, políticos y religiosos.
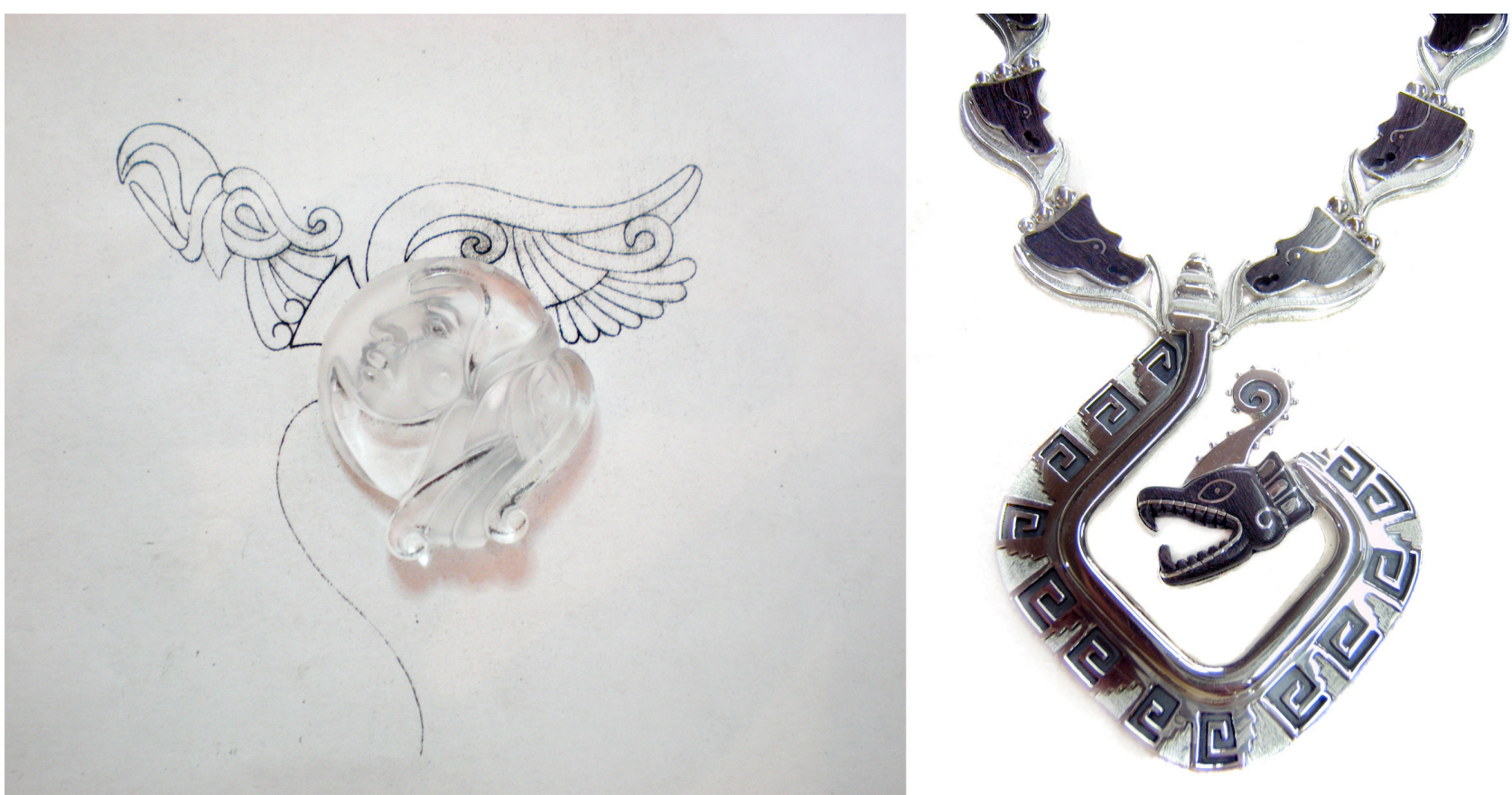

Ilustración 3. Ejemplos de joyería artesanal de inspiración prehispánica. Obras del Maestro artesano Humberto Ortiz, Taxco de Alarcón, México 2010.

\footnotetext{
${ }^{4}$ BERARDI, F. O. Op. cit. Pág. 144.

${ }^{5}$ DE LA PEÑA, F. El Movimiento Mexicanista. Imaginario prehispánico, nativismo y neotradicionalismo en el México contemporáneo. En: Ciencias Sociales y Religión. Porto Alegre, año 3, n. 3, p. 95-113. Octubre, 2001. Pág. 97.
} 
Todo cuanto ha sido expreso hasta ahora lo podemos ver plasmado en la Joyería Contemporánea mexicana que suele construir su discurso sobre la sociedad actual a través de la simbología, materiales y técnicas de las culturas locales, distinguiéndose dentro del circuito internacional al que pertenece.

La Joyería Contemporánea como fenómeno artístico internacional se establece a partir de las posibilidades participativas de la web2.0, por medio de la cual se ha establecido una red que ha unificado el movimiento por medio de plataformas representativas y ampliando sus horizontes permitiendo una constante conexión entre los artistas joyeros desde cualquier parte del globo. ${ }^{6}$ La Joyería Contemporánea al igual que el arte contemporáneo, tratando de mantener el control del circuito desde los centros hegemónicos, que en su caso corresponden a las galerías y escuelas europeas, tienen mucho interés en expandirse y englobar todos los territorios para una continua renovación de sí mismo. La demanda de productos exóticos, diferentes, desde territorios menos contaminados, el viejo recurso del "buen salvaje", surge en momentos de saturación, de recesión de los mercados artísticos centrales ${ }^{7}$ como hace notar el artista joyero chileno Nano Pulgar: "Los europeos se dieron cuenta de que por ser tan eurocéntricos se están cerrando las galerías, los coleccionistas se están muriendo y los artistas están medio aburridos ellos mismos».

El interés de los centros influyentes por los lugares y culturas exóticas se reconoce por dos hechos: la apreciación en Europa de la obra de artistas joyeros como el mexicano Jorge Manilla, que desde la influencia de su cultura de origen desarrolla un estética completamente original; y se reconoce también en la intención de exportar el "modelo" de la Joyería Contemporánea tal y como concebido en los centros hacia otras culturas, consiguiendo el comienzo de importantes eventos, como pasó en Latinoamérica a partir de Área Gris, Primer Encuentro de Joyería Contemporanea entre America Latina y Europa, que hubo lugar en México en 2010. Estos eventos generaron agrupaciones locales de joyeros que empezaron a seguir las pautas y el formato del "joyero contemporáneo". Por el otro lado estos eventos dieron visibilidad a artistas joyeros de países "periféricos" haciendo evidente a los europeos el mundo cerrado en lo que la Joyería Contemporánea está viviendo, lo que Bejamin Lignel, uno de los teóricos y protagonistas europeos de este movimiento artístico, apoda como "circuito cerrado de televisión" "donde la visibilidad y la discusión acerca de la Joyería Contemporánea recae siempre entre los mismos en un continuo proceso de auto legitimación "somos talentosos porque decimos que lo somos"». 9

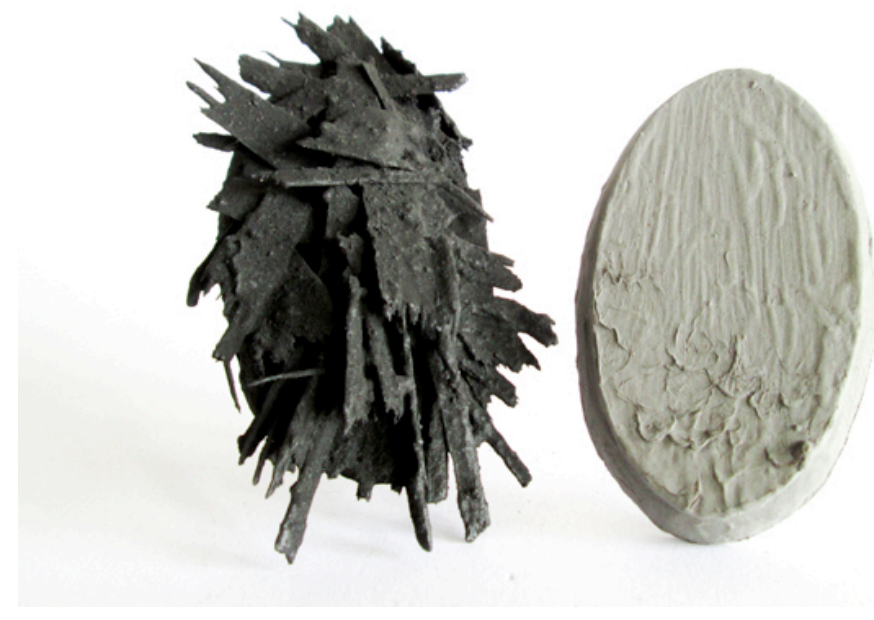

llustración 4. Jorge Manilla. Extreme Seductiveness II y Each of us is Incomplete Compared with Somebody Else, 2014.

Exponemos otro interesante efecto de la cultura global: la progresiva descentralización de las dinámicas artísticas, generando importantes eventos más allá de los circuitos establecidos, obligando de alguna manera a los críticos y curadores a desplazar su mirada hacia los "países periféricos". ${ }^{10}$ En México hemos encontrado que la influencia de la Joyería Contemporánea está al limite

\footnotetext{
${ }^{6}$ Confr. con: PIGNOTTI, C. La doble vida virtual de la Joyería Contemporánea. En: /l Congreso Internacional de Investigación en Artes Visuales: Real/Virtual. Universidad Politécnica

de Valencia. Valencia: Ed. Universidad Politécnica de Valencia, 2015. ISBN. 978-84-9048-341-1.

${ }^{7}$ PEREZ D. Pluralismo e identidad: el arte y sus fronteras. En: JIMENEZ, J, CASTRO F. (ed.) Horizontes del arte latino americano. Madrid: Ed. Tecnos, 1999. Pág. 28.

${ }^{8}$ Nano Pulgar entrevistado por Chiara Pignotti. Múnich, 2013. En: PIGNOTTI, C. Joyería Contemporánea, un nuevo fenómeno artístico. Análisis de las relaciones entre la joyería europea y mexicana en la actualidad. (Tesis doctoral) Directora: MARCOS MARTíNEZ, C. Facultad de Bellas Artes, Universidad Politécnica de Valencia. Valencia, 2016. Pág. 477.

${ }_{9}$ LIGNEL, B. CCTV. En Klint02. On line: klimt02.net/blogs/blog.php?Id=8 (Publicado: 08/05/2010. Consultado: 28/11/2013).

${ }^{10}$ Confr. con: RAMíREZ M, C. Contexturas: Lo global a partir de lo local. En: JIMENEZ, J, CASTRO F. (ed.) Horizontes del
} 
entre la mera emulación de las tendencias internacionales y la posibilidad de afirmar la importancia de esta práctica artística a nivel institucional, concursos, museos y universidades, gracias al aval del fenómeno internacional. En México los antecedentes de joyería como forma de expresión artística personal son bastante desconocidos también entre las nuevas generaciones de artistas joyeros; gracias a nuestra investigación hemos podido documentar la existencia de un fenómeno local parecido, haciendo evidente la importancia que la recuperación de su historia tiene para su autodeterminación frente a la influencia externa, pudiendo afirmar que la Joyería Contemporánea internacional ha únicamente otorgado el nombre a algo que ya existía en México. Desde la desinhibida experimentación interdisciplinaria de los años 70 algunos artistas empezaron a proponer obras muy originales como el caso de las "esculturas portantes" de Víctor Fosado, que hemos considerado el pionero del movimiento en México. Entre la década de los 80 y 90 un grupo de artistas entre los cuales Ofelia Murrieta, Lucilla Rousset y Andrés Fonseca, empezaron a proponer exposiciones colectivas de joyería bajo un tema conductor y la participación de historiadores y críticos de arte que sustentaron teóricamente estos proyectos. Los artistas se remitieron a los ideales europeos del Arts and Crafts y de la Bauhaus en la revalidación de las artes aplicadas, ámbito al que la joyería tradicionalmente pertenece, al rango de obra de arte. También otros artistas como Lorena Lazard, entre los más reconocidos, estaban trabajando con las mismas intenciones, creando pequeñas realidades aisladas, los tentativos de agrupaciones no tuvieron seguimiento, y nunca encontraron apoyo o interés institucional, la mayoría de los artistas joyeros continuaron trabajando por su cuenta hasta reencontrarse en el simposio Área Gris. De aquí la importancia de este evento como unificación del movimiento tanto a nivel global como a nivel local. Si es verdad que este evento ha revelado el europeo centrismo de este fenómeno, con la falta de implicación de los organizadores en investigar los antecedentes locales y otorgar justo merito a los citados protagonistas mexicanos, por otro lado, ha favorecido indirectamente investigaciones como la nuestra, haciendo evidente un contexto inexplorado, y alimentando al mismo tiempo, por reacción, la voluntad de los artistas locales de documentar y reafirmar su historia que ha sido ignorada.

Concluyendo podemos decir que la Joyería Contemporánea puede resultar, aunque involuntariamente, otro aspecto de la homologación cultural imperante que tiende a superar y desvirtuar las diversidades culturales, por sus condicionamientos europeo céntricos; pero también encontramos en el trabajo de los artistas joyeros validas posibilidades de revalidación de las artes y artesanías locales, así como una posibilidad de afirmación desde países "periféricos" de cambios de paradigma dentro de la cultura hegemónica. Analizando las dinámicas y obras de los artistas joyeros mexicanos y europeos dentro del contexto de la globalización, hemos visto como las influencias centro/periferia empiezan a ser recíprocas y no sólo unidireccionales; hemos visto como la cultura local se presta cada vez menos al juego de su papel de alteridad en un mundo centralizado en la cultura occidental, reformulando nuevas identidades proyectadas hacia la aldea global, a través de una nueva joyería que trata de representarlas.
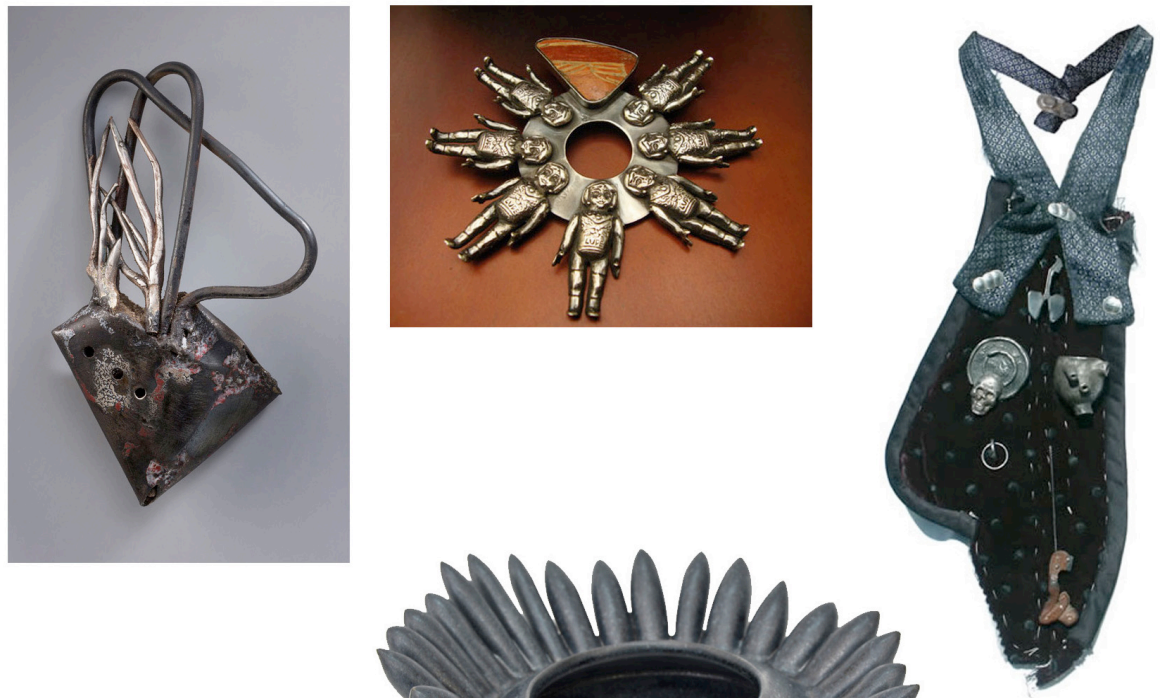

Ilustración 5. Desde Izquierda: Lorena Lazard. Origen \#2, 2014; Ofelia Murrieta. Sin título, 2012; Andrés Fonseca. Sin título, 2010; abajo: Edgar López. Movement, 2014.

arte latino americano. Madrid: Ed. Tecnos, 1999. Págs. 69-81. 


\section{FUENTES REFERENCIALES.}

BERARDI F. La fábrica de la infelicidad. Madrid: Ed. Traficantes de Sueños. 2003.

DE LA PEÑA, F. El Movimiento Mexicanista. Imaginario prehispánico, nativismo y neotradicionalismo en el México contemporáneo. En: Ciencias Sociales y Religión. Porto Alegre, año 3, n. 3, p. 95-113. Octubre, 2001.

de Valencia. Valencia: Ed. Universidad Politécnica de Valencia, 2015. ISBN. 978-84-9048-341-1.

JIMENEZ, J, CASTRO F. (ed.) Horizontes del arte latino americano. Madrid: Ed. Tecnos, 1999.

MAC CANNELL, D. El Turista. Una nueva teoría de la clase ociosa. Barcelona: Ed. Melusina, 2003.

MARCOS MARTÍNEZ, C.; PIGNOTTI, C. La recuperación de la manualidad frente a la crisis impuesta por la cultura globalizadora dominante. En: I Congreso de Investigación en Artes Visuales: El Arte Necesario. Valencia: Ed. ANIAV- DEFORMA Cultura On line, 2013. ISSN 2254-2272.

MOSQUERA, G. Caminar con el diablo. Textos sobre arte, internacionalismo y culturas. Madrid: Ed. EXIT Publicaciones, 2010.

PIGNOTTI, C. Joyería Contemporánea, un nuevo fenómeno artístico. Análisis de las relaciones entre la joyería europea y mexicana en la actualidad. (Tesis doctoral) Directora: MARCOS MARTínEZ, C. Facultad de Bellas Artes, Universidad Politécnica de Valencia. Valencia, 2016. Pág. 477.

PIGNOTTI, C. La doble vida virtual de la Joyería Contemporánea. En: /l Congreso Internacional de Investigación en Artes Visuales: Real/Virtual. Universidad Politécnica. Valencia: Ed. Universidad Politécnica de Valencia, 2015. ISBN. 978-84-9048-341-1.

SKINNER, D. (ed.) Contemporary Jewellery in Perspective. New York: Ed. Lark Jewelry \& Beading, 2013. 